\title{
Very-early Guillain-Barré syndrome: Clinical characteristics, electrophysiological findings, and short-term functional outcome
}

\author{
Juan C. López-Hernández ${ }^{1 *}$, Raúl N. May-Mas ${ }^{1}$, Javier A. Galnares-Olalde ${ }^{1}$, Lisette Bazán-Rodríguez", \\ Adib J. de-Saráchaga ${ }^{1}$, Eunice Martínez-Jiménez ${ }^{1}$, Jorge Burgos-Centeno², \\ Elizabeth León-Manríquez ${ }^{1}$, and Edwin S. Vargas-Cañas ${ }^{1}$ \\ ${ }^{1}$ Department of Neuromuscular Diseases; ${ }^{2}$ Department of Neurophysiology, Instituto Nacional de Neurología y Neurocirugía, Mexico City, Mexico
}

\begin{abstract}
Background: Guillain-Barré syndrome (GBS) patients who present very early (< 4 days) to health-care services generally have severe clinical forms due to rapid progression. Little information exists on the clinical and short-term functional prognosis in patients with very-early GBS (VEGBS). Methods: A prospective cohort study was conducted. We performed KaplanMeier survival analysis to observe the recovery of independent gait between groups, where a log-rank value $<0.05$ was considered significant. All statistical analyzes were performed using SPSS version 22. Results: Ninety-nine patients were included in the study. Mean age was $46.7 \pm 16.7$ years, $61.9 \%$ were male. Regarding nerve conduction studies, the most frequent electrophysiological variants in the very early-onset GBS group were axonal (38.7\%). Twenty-three percent were classified as equivocal. In the GBS group > 4 days, the most frequent electrophysiological variant was acute inflammatory demyelinating polyneuropathy (52.1\%). Conclusion: Patients with VEGBS do not present different clinical characteristics, nor severity or poor short-term outcome in our population compared to different GBS presentations. Only mechanical ventilation requirement and distal compound muscle action potential reduction are associated with poor outcome in this subset of patients.
\end{abstract}

Key words: Guillain-Barré syndrome. Very early. Neuropathy. AIDP. AMAN.

\section{Síndrome de Guillain-Barré muy temprano: características clínicas, hallazgos electrofisiológicos y resultado funcional a corto plazo}

\section{Resumen}

Antecedentes: Los pacientes con síndrome de Guillain Barré (SGB) que se presentan muy temprano (menos de 4 días) a los servicios de salud generalmente tienen formas clínicas graves debido a la rápida progresión. Existe poca información sobre el pronóstico clínico y funcional a corto plazo en pacientes con presentación ultra temprana. Métodos: Se realizó un estudio de cohorte prospectivo. Realizamos un análisis de supervivencia de Kaplan-Meier para observar la recuperación de la marcha independiente entre los grupos, donde un valor de log-rank < 0.05 se consideró significativo. Todos los análisis estadísticos se realizaron con SPSS versión 22. Resultados: Se incluyeron 99 pacientes. La media de edad fue de 46.7

\section{Correspondence:}

*Juan C. López-Hernández

E-mail: clinicaneuromuscular.innn@gmail.com

2604-6180/ (C) 2021 Academia Mexicana de Neurolo (http://creativecommons.org/licenses/by-nc-nd/4.0/).
Date of reception: 17-03-2021

Date of acceptance: 27-05-2021

DOI: $10.24875 / R M N .21000024$
Available online: 01-10-2021

Rev Mex Neuroci. 2021;22(5):173-179

www.revmexneurociencia.com 
\pm 16.7 años, el $61.9 \%$ eran varones. En cuanto a los estudios de conducción nerviosa, las variantes electrofisiológicas más frecuentes en el grupo de SGB de inicio muy precoz fueron axonales (38.7\%). El $23 \%$ se clasificó como equívoco. En el grupo de SGB > 4 días, la variante electrofisiológica más frecuente fue AIDP (52.1\%). Conclusión: Los pacientes con presentación ultratemprana no presentan características clínicas diferentes, ni gravedad ni mala evolución a corto plazo en nuestra población en comparación con diferentes presentaciones de SGB. Solo el requerimiento de ventilación mecánica y la reducción de la CMAP distal se asocian con un resultado deficiente en este subconjunto de pacientes.

Palabras clave: Síndrome de Guillain-Barré syndrome. Muy temprano. Neuropatía. PDIA. NAMA.

\section{Introduction}

Guillain-Barré syndrome (GBS) is considered the most common acute inflammatory polyneuropathy worldwide, with an incidence of $0.16-3.0 / 100,000$ person-years ${ }^{1}$. It presents with variable acute weakness of the four limbs, sensory symptoms, and decreased or absent deep tendon reflexes. GBS symptoms occur in $<4$ weeks, with its maximum nadir 2 weeks after symptom onset. Twenty-five percent of patients require invasive mechanical ventilation (IMV) support and $5 \%$ die despite immunological treatment ${ }^{2}$.

The three electrophysiological variants reported in the literature are acute inflammatory demyelinating polyneuropathy (AIDP) and the axonal forms that include acute motor axonal neuropathy (AMAN) and acute sensorimotor axonal neuropathy (ASMAN) ${ }^{3}$. Multiple electrophysiological criteria exist to classify GBS variants. It is still debated if GBS variants can be diagnosed with a single electrophysiological study as some authors recommend one while others two. Time from symptom onset to electrophysiological testing is crucial to identify each variant properly. Very-early stage includes the first 4 days since symptom onset and early stage from 5 to 7-10 days 4 . In very-early GBS (VEGBS), the current topic for discussion is the requirement of a second electrophysiological study, as only $20 \%$ of the studies meet criteria for some variant with a single study.

GBS patients who present very early to health-care services generally have severe clinical forms due to rapid progression. Little information exists on the clinical and short-term functional prognosis in patients with VEGBS.

\section{Materials and methods}

A prospective cohort study in a single healthcare center in Mexico was conducted. We included patients with GBS defined by Asbury criteria from January 1, 2018 , to June $30,2020^{5}$. Patients admitted to the hospital $\leq 4$ days since symptom onset were classified as
VEGBS. Clinical data obtained included: age, gender, history of the previous infection, assessment of muscle strength through the Medical Research Council (MRC) scale at diagnosis, GBS disability scale (GDS) at diagnosis, EGRIS and mEGOS sore at admission, requirement for IMV, and treatment (IVIG, plasma exchange, or conservative). Patients were classified clinically according to Wakerley's criteria ${ }^{6-8}$. Laboratory test results were obtained from all patients on admission: total leukocyte count, glucose (mg/dl), sodium (meq/dl), and serum albumin $(\mathrm{g} / \mathrm{dl})$. We considered hyponatremia on admission as $\mathrm{Na}<135 \mathrm{meq} / \mathrm{dl}$. Cerebrospinal fluid (CSF) analysis was also included; we defined albuminocytological dissociation as proteins $>45 \mathrm{mg} / \mathrm{dl}$ with cell count $<50$.

Nerve conduction studies were performed by a highly experienced neurophysiologist, using Cadwell Sierra Summit and Nicolet Viking Electromyograph. Electrophysiological protocol includes median, ulnar, peroneal, and tibial for motor examination and median, ulnar and sural for sensory examination. We included time (days) of the study since symptom onset, distal latency (ms), nerve conduction velocity $(\mathrm{m} / \mathrm{s})$, and distal and proximal compound muscle action potential (CMAP) amplitudes $(\mathrm{mV})$ from each motor nerve explored. We defined electrophysiological variants based on Hadden's criteria9.

We define favorable short-term outcome (3 months) in patients who have not lost independent gait (GDS $\leq 2)$ on admission or those who recovered independent gait during or before 3 months follow-up. Poor outcome was defined as patients who had not recovered independent gait (GDS $\geq 3$ ) at 3 months follow-up.

\section{Statistical analysis}

For the descriptive analysis, distribution of continuous variables was determined by the KolmogorovSmirnov test. Variables were described as mean, standard deviation (SD) or medians, and interquartile range according to distribution. Categorical variables were described as frequencies and percentages. To look for 
Table 1. Baseline characteristics

\begin{tabular}{|c|c|c|c|}
\hline & $\begin{array}{l}\leq 4 \text { days since symptom onset } \\
\qquad(\mathrm{n}=35)\end{array}$ & $\begin{array}{l}>4 \text { days since symptom onset } \\
\qquad(n=62)\end{array}$ & p value \\
\hline $\begin{array}{l}\text { Demographics } \\
\text { Age (years), mean, SD } \\
\text { Gender (male), n (\%) }\end{array}$ & $\begin{array}{l}48.1 \pm 17.2 \\
22(62.8)\end{array}$ & $\begin{array}{l}45.9 \pm 16.6 \\
38(61.2)\end{array}$ & $\begin{array}{l}0.54 \\
>0.99\end{array}$ \\
\hline $\begin{array}{l}\text { History } \\
\text { Respiratory infection, } \mathrm{n}(\%) \\
\text { Diarrhea, } \mathrm{n}(\%) \\
\text { MRC score at diagnosis, SD } \\
\text { GDS score, median (IQR) } \\
\text { mEGOS score, median (IQR) }\end{array}$ & $\begin{array}{c}12(34.2) \\
9(25.7) \\
32.8 \pm 16.1 \\
4(4.0-4.75) \\
6(4-7)\end{array}$ & $\begin{array}{c}10(16.1) \\
26(41.9) \\
34.6 \pm 17.4 \\
4(4.0-5.0) \\
5(3-7)\end{array}$ & $\begin{array}{l}0.047 \\
0.12 \\
0.75 \\
0.38 \\
0.58\end{array}$ \\
\hline $\begin{array}{l}\text { Cranial nerve involvement } \\
\text { Unilateral facial palsy, } \mathrm{n}(\%) \\
\text { Bilateral facial palsy, } \mathrm{n}(\%) \\
\text { Ocular compromise, } \mathrm{n}(\%) \\
\text { Bulbar compromise, } \mathrm{n}(\%) \\
\text { EGRIS score, median (IQR) } \\
\text { Dysautonomia (\%) } \\
\text { Blood pressure variability, } \mathrm{n}(\%) \\
\text { Heart rate variability, } \mathrm{n}(\%) \\
\text { Mechanical ventilation progression } \\
\text { Mechanical ventilation requirement, } \mathrm{n}(\%) \\
\text { Mechanical ventilation duration, days, median (IOR) }\end{array}$ & $\begin{array}{c}0(0) \\
14(40) \\
10(28.5) \\
15(42.8) \\
4(3-7) \\
13(37.1) \\
9(25.7) \\
8(22.8) \\
11(31.4) \\
16(45.7) \\
20(10.25-85)\end{array}$ & $\begin{array}{c}12(19.3) \\
18(29) \\
22(35.4) \\
21(33.8) \\
3(2-5) \\
15(24.1) \\
10(16.1) \\
10(16.1) \\
8(12.9) \\
16(25.8) \\
42(10-73)\end{array}$ & $\begin{array}{c}0.004 \\
0.36 \\
0.38 \\
0.39 \\
0.002 \\
0.24 \\
0.29 \\
0.42 \\
0.028 \\
0.071 \\
0.50\end{array}$ \\
\hline $\begin{array}{l}\text { Clinical GBS variants } \\
\text { Sensorimotor, } \mathrm{n}(\%) \\
\text { Pure motor, } \mathrm{n}(\%) \\
\text { Miller Fisher/Overlap, } \mathrm{n}(\%) \\
\text { Pharyngeal-cervical-brachial, } \mathrm{n}(\%) \\
\text { Facial biparesis-Arreflexia, } \mathrm{n}(\%)\end{array}$ & $\begin{array}{c}19(54.2) \\
11(31.4) \\
3(8.5) \\
2(5.7) \\
0(0)\end{array}$ & $\begin{array}{c}43(69.3) \\
21(33.8) \\
6(9.6) \\
0(0) \\
1(1.6)\end{array}$ & $\begin{array}{c}0.18 \\
0.13 \\
>0.99 \\
0.12 \\
0.99\end{array}$ \\
\hline $\begin{array}{l}\text { Tratamiento } \\
\text { Conservative, n (\%) } \\
\text { IVIG, n (\%) } \\
\text { PE, } \mathrm{n}(\%) \\
\text { Independent gait at three months, } \mathrm{n}(\%)\end{array}$ & $\begin{array}{c}4(11.4) \\
25(71.4) \\
6(17.1) \\
11 / 25(44)\end{array}$ & $\begin{array}{c}11(17.7) \\
26(41.9) \\
25(40.3) \\
28 / 45(62.2)\end{array}$ & 0.018 \\
\hline
\end{tabular}

IVIG: intravenous immunoglobulin, PE: plasma exchange.

differences between groups, we used $\times 2$ test and Fisher's exact test for categorical variables, Student's $\mathrm{t}$ test to compare means, and Mann-Whitney U-test to compare medians. $p<0.05$ was considered statistically significant.

We performed Kaplan-Meier survival analysis to observe the recovery of independent gait between groups, where a log-rank value $<0.05$ was considered significant. All statistical analyses were performed using SPSS version 22.

\section{Results}

Ninety-nine patients were included in the study. Mean age was $46.7 \pm 16.7$ years, $61.9 \%$ were male, and $35(36 \%)$ patients were admitted in VEGBS. We collected 77 nerve conduction studies performed within
7 days (IQR4-7) from symptom onset. Baseline characteristics are summarized in table 1.

When comparing clinical characteristics of very early-onset GBS patients versus $>4$ days, we observed significant differences in preceding respiratory tract infection $(34.2 \%$ vs. $16.1 \%, p=0.047)$, unilateral facial palsy ( $0 \%$ vs. $19.3 \%, p=0.004)$, EGRIS score (4 [3-7] vs. 3 [2-5], $p=0.002)$, and mechanical ventilation requirement $(31.4 \%$ vs. $12.9 \%, p=0.028)$. The Kaplan-Meier survival analysis for independent gait at 3-months between very early and $>4$ days GBS patients is shown in Figure 1.

Regarding nerve conduction studies, the most frequent electrophysiological variants in the very early-onset GBS group were axonal (38.7\%). Twenty-three percent were classified as equivocal. In the GBS group > 4 days, the most frequent electrophysiological variant was AIDP (52.1\%) and eight studies (17.3\%) were 
Table 2. Electrophysiological and laboratory characteristics

\begin{tabular}{|c|c|c|c|}
\hline & $\begin{array}{c}\leq 4 \text { days since symptom } \\
\text { onset }(n=35)\end{array}$ & $\begin{array}{c}>4 \text { days since symptom } \\
\text { onset }(n=62)\end{array}$ & Valor de $\mathbf{p}$ \\
\hline Time from symptom onset to NCS (días), median (IOR) & $4(3-5)$ & $7.5(6-8)$ & $<0.001$ \\
\hline AIDP, n (\%) & $10 / 31(32.2)$ & $24 / 46(52.1)$ & 0.10 \\
\hline Axonal n (\%) & $12 / 31(38.7)$ & $13 / 46(28.2)$ & 0.45 \\
\hline Not exitable, n (\%) & $2 / 31(6.4)$ & $2 / 46(4.3)$ & 0.99 \\
\hline Equivocal, n (\%) & $7 / 31(22.5)$ & $8 / 46(17.3)$ & 0.57 \\
\hline Median nerve CMAP (mV), median (IQR) & $1.5(0.1-5.6)$ & $1.7(0.6-3.0)$ & 0.96 \\
\hline Ulnar nerve CMAP (mV), median (IQR) & $1.2(0.0-4.3)$ & $1.8(0.3-4.1)$ & 0.32 \\
\hline Tibial nerve CMAP (mV), median (IQR) & $0.8(0.0-5.2)$ & $0.85(0.1-3.0)$ & 0.99 \\
\hline Peroneal nerve CMAP (mV), mediana (IQR) & $0.4(0.0-3.6)$ & $0.8(0.1-2.5)$ & 084 \\
\hline CSF proteins (mgs/dl), mediana (IQR) & $28.5(22.5-45.75)$ & $78(36-111)$ & $<0.001$ \\
\hline Albuminocytological dissociation, n (\%). & $8 / 26(30.7)$ & $32 / 50(64)$ & 0.008 \\
\hline Sodium at admission, median (IQR) & $140(137-143)$ & $137(135-140)$ & 0.003 \\
\hline Albumin at admission, median (RIQ) & $4.3(3.9-4.5)$ & $4.2(3.7-5.0)$ & 0.84 \\
\hline Leukocyte count at admission, median (IQR) & $8.9(6.85-10.6)$ & $10.3(8.7-13.93)$ & 0.028 \\
\hline
\end{tabular}

IQR: interquartile range; CMAP: compound muscle action potential; AIDP: acute inflammatory demyelinating polyneuropathy.

classified as equivocal. When carrying out comparative analysis, we observed a significant difference in the study time (4 [3-5] vs. 7.5 [6-8], $p \leq 0.001$ ] between groups. There were no significant differences between the frequency of the different electrophysiological variants and in the distal PAMC of motor nerves explored (Table 2).

We observed significant differences in CSF protein levels (28.5 [22.5-45.75] vs. 78 [36-111] mg/dl, $p \leq 0.001)$, serum sodium levels at admission (140 [137-143] vs. 137 [135-140] mqs/dl, $p=0.003$ ), and leukocyte count (8.9 [6.85-10.6] vs. 10.3 [8.7-13.93] $p=0.028)$. We observed increased frequency of hyponatremia $(\mathrm{Na}<135 \mathrm{meq} / \mathrm{dl})$ at admission in the group of patients with GBS $>4$ days versus very-early stages $(2.8 \%$ vs. $20.9 \%, p=0.017$ ).

\section{Discussion}

GBS is the most common cause of acute flaccid paralysis worldwide, with an incidence of 0.16-3.0/100,000 person-years ${ }^{1}$. Several clinical factors for poor short- and long-term outcome include old age, preceding diarrhea, pure motor clinical presentation, low MRC score, high GDS score, dysautonomia, and IMV requirement ${ }^{10}$. In our study, we did not identify statistical differences between MRC score, GDS, and dysautonomia. This may be related to a reference bias, as our hospital is a reference center for the diagnosis and treatment of neurological conditions.

In Latin American countries and Asia, the electrophysiological variant AMAN is considered as an independent factor for poor outcome. This is related to our higher prevalence of this variant and preceding diarrhea due to Campylobacter jejuni infection, producing antibodies against axonal gangliosides secondary to molecular mimicry. Surprisingly, in our patients with VEGBS, we identified a higher prevalence of preceding respiratory tract infection, different to the literature reports which report faster symptom progression in preceding diarrhea ${ }^{7}$. Typically, respiratory infections are associated with viral agents such as Influenza, cytomegalovirus, and Epstein-Barr, although many other agents may be associated.

Mechanical ventilation is related to both severe presentations and poor outcome ${ }^{6,10}$. The EGRIS scale assesses the risk of IMV requirement, and it gives a higher score in acute presentations. Moreover, IMV is associated with longer hospital stay and a poor short- and long-term outcome. In our population, 
patients with VEGBS had a higher score on the EGRIS scale. Furthermore, we observed a greater number of patients progressing to the IMV requirement during the $1^{\text {st }}$ week of hospitalization. Nonetheless, we did not observe significant differences IMV duration during hospital stay.

In the experimental models of allergic polyneuritis, severe inflammatory changes are observed since the $1^{\text {st }}$ day of presentation, which may explain the rapid and severe progression of symptoms in some patients with GBS $^{11}$. Indeed, there are reports of fulminant GBS which includes rapid progression of symptoms attending the emergency services within hours ${ }^{12}$. Similarly, patients with GBS who are admitted within 4 days since symptom onset (very-early stages) represent a severe form of GBS. However, there is few clinical information and outcome in this subset of patients. In VEGBS, clinical studies have focused on describing the electrophysiological findings ${ }^{13}$.

VEGBS findings in nerve conduction studies include F-wave abnormalities and prolonged latencies on the periphery nerve ${ }^{14}$. Reports mention that a large percentage of nerve conduction studies performed in early-stage GBS ( $\leq 4$ days) days do not meet criteria for some type of variant. Berciano et al. report that only $20 \%$ of the studies meet criteria for axonal variants and none for AIDP in very-early stages, and after conducting a second follow-up study, $46.7 \%$ meet criteria for the AIDP variant, $46.7 \%$ for axonal variants, and only $6.6 \%$ remain unclassifiable 4 . Another study by Uncini et al. reported 55 patients with GBS who underwent several nerve conductions studies. The first one was carried out on day 9 (range 2-15), with 37 patients with AIDP diagnosis, ten with axonal variants, and eight were classified as equivocal. After conducting the second study at day 28 (range 7-70), several studies completed criteria for axonal variants, including seven that were classified as AIDP in the first study ${ }^{15}$. In our population, the most frequent electrophysiological variants were axonal $(38.7 \%)$, and only $22.5 \%$ of the studies did not meet criteria for any variant, differing from what was previously reported. We did not perform a second electrophysiological study. It is crucial to classify GBS patients into electrophysiological variants, as axonal variants confer a worse prognosis than AIDP. Therefore, it is currently suggested to carry out two nerve conduction studies during follow-up in patients in which the first study was performed in very early stages ${ }^{3,10}$.

Severe axonal damage is observed with recording of distal CMAP in each motor nerve examined. Cornblath et al. reported that the CMAP $\leq 20 \%$ of Lower Normal

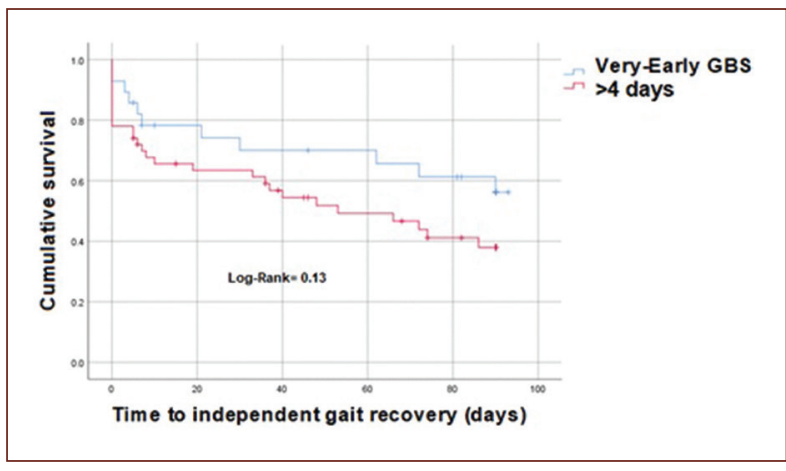

Figure 1. Independent gait at 3-month follow-up in patients with symptom onset to admission $\leq 4$ days (very-early $\mathrm{GBS}$ ) versus $>4$ days.

Limit (in our population $\leq 1 \mathrm{mV}$ ) is related to a worse functional prognosis ${ }^{16}$. Interestingly, we did not observe differences in distal CMAP between groups (Table 2), but when comparing only patients with VEGBS with favorable versus poor 3-month outcome (Table 3), we observed significant differences in distal PAMC in motor nerves.

The GDS, which is the most used in observational studies and in clinical trials, was described by Hughes since 1978 and basically assesses the functionality of the lower extremities in its first 4 points. For this reason, our consideration is that the Axonal damage to the peroneal nerve directly impacts functional prognosis, as this nerve is responsible for innervating the muscles responsible dorsiflexion ${ }^{17}$. In addition, physiological mechanisms of peripheral nerve regeneration take longer time in distal nerves ${ }^{18}$.

Increase in CSF protein concentration in patients with GBS > 4 days is an expected result; this is most commonly finding it after 10 days of evolution from the beginning of the symptoms ${ }^{1}$. In our patients with VEGBS have fewer protein levels in CSF and less cytological albumin dissociation ( $25 \%$ vs. $50 \%, p=0.008)$. This result is consistent with literature reports.

Hyponatremia is the most common electrolyte abnormality in hospitalized patients. In GBS, it occurs in up to $37 \%$ of patients. We observed a higher frequency of hyponatremia in patients with GBS > 4 days. The pathophysiological mechanism of hyponatremia is not completely established, the main theory is that it is secondary to cardiovascular dysautonomia caused by the release of atrial natriuretic peptide and the subsequent urinary loss of sodium ${ }^{19}$. In patients treated with IVIG, another mechanism is pseudohyponatremia. Interestingly, we did not observe differences in 
Table 3. Clinical and paraclinical comparison in very-early GBS patients between favorable and poor outcome

\begin{tabular}{|c|c|c|c|}
\hline & Poor prognosis $(n=14)$ & Favorable prognosis $(\mathrm{n}=11$ ) & $\mathrm{p}$ value \\
\hline Age (years) mean, SD & $51.5 \pm 19.8$ & $42.5 \pm 17.2$ & 0.24 \\
\hline Diarrhea, n (\%) & $6(42.8)$ & $2(18.1)$ & 0.23 \\
\hline MRC score $<30$ points, n (\%) & $7(50)$ & $8(72.7)$ & 0.41 \\
\hline Dysautonomia, n (\%) & $7(50)$ & $6(54.5)$ & 0.99 \\
\hline Mechanical ventilation requirement, $\mathrm{n}(\%)$ & $13(92.8)$ & $3(27.2)$ & 0.002 \\
\hline AIDP, n (\%) & $3 / 13(23)$ & $4 / 11(36.3)$ & 0.65 \\
\hline Axonal n (\%) & $9 / 13(69.2)$ & $5 / 11(45.4)$ & 0.40 \\
\hline Median distal CMAP (mV), median (IQR) & $0.3(0.0-1.7)$ & $5.2(2.3-6.5)$ & 0.019 \\
\hline Ulnar distal CMAP (mV), median (IQR) & $0.1(0.0-1.8)$ & $4.3(1.0-6.5)$ & 0.016 \\
\hline Tibial distal CMAP (mV), median (IOR) & $0.4(0.1-2.5)$ & $5.2(1.1-8.5)$ & 0.059 \\
\hline Peroneal distal CMAP (mV), median (IOR) & $0.2(0.0-1.1)$ & $3.2(1.0-4.7)$ & 0.045 \\
\hline Sodium at admission, median (IQR) & $140(138-141)$ & $139(137-142)$ & 0.73 \\
\hline Albumin at admission (g/dl), median (IQR) & $4.1(3.5-4.4)$ & $4.4(3.5-4.9)$ & 0.35 \\
\hline Leukocyte at admission, median (IOR) & $8.9(6.6-11.7)$ & $8.9(7.6-10.4)$ & 0.76 \\
\hline
\end{tabular}

IQR: interquartile range; CMAP: compound muscle action potential; AIDP: acute inflammatory demyelinating polyneuropathy.

dysautonomia frequency. We also did not found any differences in EGRIS and mEGOS scores. In the survival analysis using the Kaplan-Meier curve, we observed that patients with VEGBS at 3 months had a lower rate of independent walking.

A limitation to the present study includes its retrospective character. Furthermore, we did not perform a second electrophysiological study to identify patients with equivocal initial classification. Moreover, at the end of follow-up the Kaplan-Meier curves open, perhaps if we had a longer follow-up (6 months) we would find a significant difference.

\section{Conclusion}

Patients with VEGBS do not present different clinical characteristics, nor severity, or poor short-term outcome in our population compared to different GBS presentations. Only mechanical ventilation requirement and distal CMAP reduction are associated with poor outcome in this subset of patients. This may set background for further prospective studies to identify optimal timing and number of nerve conduction studies and to identify factor associated with poor outcome.

\section{Funding}

This research has not received any grant from agencies in the public, commercial, or non-profit sectors.

\section{Conflicts of interest}

The authors declare no conflicts of interest.

\section{Ethical disclosures}

Protection of human and animal subjects. The authors declare that no experiments were performed on humans or animals for this study.

Confidentiality of data. The authors declare that they have followed the protocols of their work center on the publication of patient data.

Right to privacy and informed consent. The authors declare that no patient data appear in this article.

\section{References}

1. Sejvar JJ, Baughman AL, Wise M, Morgan OW. Population incidence of Guillain-Barré syndrome: a systematic review and meta-analysis. Neuroepidemiology. 2011;36:123-33.

2. van den Berg B, Walgaard C, Drenthen J, Fokke C, Jacobs BC, van Doorn PA. Guillain-Barré syndrome: pathogenesis, diagnosis, treatment and prognosis. Nat Rev Neurol. 2014;10:469-82. 
3. Uncini A, Kuwabara S. The electrodiagnosis of Guillain-Barré syndrome subtypes: where do we stand? Clin Neurophysiol. 2018;129:2586-93.

4. Berciano J, Orizaola P, Gallardo E, Pelayo-Negro AL, Sánchez-Juan P, Infante J, et al. Very early Guillain-Barré syndrome: A clinical-electrophysiological and ultrasonographic study. Clin Neurophysiol Pract. 2019;5:1-9.

5. Asbury AK, Cornblath DR. Assessment of current diagnostic criteria for Guillain-Barré syndrome. Ann Neurol. 1990;27 Suppl: S21-4.

6. Walgaard C, Lingsma HF, Ruts L, Drenthen J, van Koningsveld R, Garssen MJ, et al. Prediction of respiratory insufficiency in Guillain-Barré syndrome. Ann Neurol. 2010;67:781-7.

7. Walgaard C, Lingsma HF, Ruts L, van Doorn PA, Steyerberg EW, Jacobs BC. Early recognition of poor prognosis in Guillain-Barre syndrome. Neurology. 2011;76:968-75.

8. Wakerley BR, Uncin A, Yuki N, GBS Classification Group. Guillain-Barré and Miller Fisher syndromes new diagnostic classification. Nat Rev Neurol. 2014;10:537-44

9. Hadden RD, Cornblath DR, Hughes RA, Zielasek J, Hartung HP Toyka KV, et al. Electrophysiological classification of Guillain-Barré syndrome: clinical associations and outcome. Plasma Exchange/Sandoglobulin Guillain-Barré Syndrome Trial Group. Ann Neurol. 1998;44:780-8.

10. López-Hernández JC, Colunga-Lozano LE, Garcia-Trejo S, Gomez-Figueroa E, Delgado-Garcia G, Bazán-Rodríguez L, et al. Electrophysiological subtypes and associated prognosis factors of Mexican adults diagnosed with Guillain-Barré syndrome, a single center experience. J Clin Neurosci. 2020;80:292-7.
11. Berciano J. Axonal degeneration in Guillain-Barré syndrome: a reappraisal. J Neurol. 2020;2020:10034.

12. Berciano J, Figols J, García A, Calle E, Illa I, Lafarga M, et al. Fulminant Guillain-Barré syndrome with universal inexcitability of peripheral nerves: a clinicopathological study. Muscle Nerve. 1997;20:846-57.

13. Khalili-Shirazi A, Gregson N, Gray I, Rees J, Winer J, Hughes R. Antiganglioside antibodies in Guillain-Barré syndrome after a recent cytomegalovirus infection. J Neurol Neurosurg Psychiatry. 1999;66:376-9.

14. Albertí MA, Alentorn A, Martínez-Yelamos S, Martínez-Matos JA, Povedano $\mathrm{M}$, Montero J, et al. Very early electrodiagnostic findings in Guillain-Barré syndrome. J Peripher Nerv Syst. 2011;16:136-42.

15. Uncini A, Manzoli C, Notturno F, Capasso M. Pitfalls in electrodiagnosis of Guillain-Barré syndrome subtypes. J Neurol Neurosurg Psychiatry. 2010;81:1157-63.

16. Cornblath DR, Mellits ED, Griffin JW, McKhann GM, Albers JW, Miller RG, et al. Motor conduction studies in Guillain-Barré syndrome: description and prognostic value. Ann Neurol. 1988;23:354-9.

17. Hughes RA, Newsom-Davis JM, Perkin GD, Pierce JM. Controlled trial prednisolone in acute polyneuropathy. Lancet. 1978;2:750-3.

18. Scheib J, Höke A. Advances in peripheral nerve regeneration. Nat Rev Neurol. 2013;9:668-76.

19. Hiew FL, Winer JB, Rajabally YA. Hyponatraemia in Guillain-Barré syndrome revisited. Acta Neurol Scand. 2016;133:295-301. 